\title{
Discoloration of manually fabricated resins and industrially fabricated CAD/ CAM blocks versus glass-ceramic: Effect of storage media, duration, and subsequent polishing
}

\author{
Bogna STAWARCZYK ${ }^{1}$, Beatrice SENER ${ }^{2}$, Albert TROTTMANN ${ }^{3}$, Malgorzata ROOS ${ }^{4}$, Mutlu ÖZCAN ${ }^{3}$ \\ and Christoph H. F. HÄMMERLE ${ }^{3}$
}

\author{
${ }^{1}$ Department of Prosthodontics, Dental School, Ludwig-Maximilian University of Munich, Goethestrasse 70, 80336 Munich, Germany \\ ${ }^{2}$ Clinic of Preventive Dentistry, Periodontology and Cariology, Center of Dental Medicine, University of Zurich, Plattenstrasse 11, 8032 Zurich, \\ Switzerland \\ ${ }^{3}$ Clinic of Fixed and Removable Prosthodontics and Dental Material Science, Center of Dental Medicine, University of Zurich, Plattenstrasse 11, 8032 \\ Zurich, Switzerland \\ ${ }^{4}$ Division of Biostatistics, Institute of Social and Preventive Medicine, University of Zurich, Hirschengraben 84, 8001 Zurich, Switzerland \\ Corresponding author, Bogna STAWARCZYK; E-mail: bogna.stawarczyk@med.uni-muenchen.de
}

\begin{abstract}
This study determined the discoloration of five CAD/CAM resins, four manually polymerized resins, and glass-ceramic as control group. Specimens were divided into three groups $(N=300, n=30)$ to be stored in coffee, black tea and red wine $(n=10)$. The discoloration was measured using a spectrophotometer after 1, 7, 29, 90, 180 days storage. All tested groups showed color change $(\Delta E)$ at all time points. The manually polymerized resin composites GD (Gradia) and CM (CronMix K), and the CAD/CAM resin composite HC (Blanc High-class) showed significantly higher $\Delta E$ compared to all other groups in all tested media. The discoloration was extrinsic and decreased after polishing for the majority of the tested materials. Except CAD/CAM resin HC (Blanc High-class), all CAD/CAM resins showed similar color stability compared to the control group.
\end{abstract}

Keywords: CAD/CAM resins, Polymeric blocks, Discoloration, Aging

\section{INTRODUCTION}

The CAD/CAM milling of resin blocks for temporary fixed dental prostheses (FDPs) fabricated under controlled and optimized manufacturing conditions enables the production of reconstructions with higher flexural strengths than those of manually polymerized ones $^{1-3)}$. Such CAD/CAM resin blocks are industrially polymerized under standardized parameters at high temperature and pressure to assure that the microstructure and the mechanical properties of the resin blocks exhibit constant quality. The polymerization parameters are fundamental for the mechanical properties ${ }^{4}$. Hence, the resin CAD/CAM blocks can be considered for long-term reconstructions. Industrially or manually polymerized temporaries are made of either PMMA-based or composite resins, each having slightly different chemical and physical properties ${ }^{5}$.

Resin restorations are more fracture resistant than glass-ceramics ${ }^{3)}$, especially in thin reconstructions ${ }^{6,7)}$. The mechanical properties such as flexural strength and enamel antagonist wear characteristics of resin-based materials offer some advantages over glass-ceramics ${ }^{8-10)}$. Therefore, recently introduced CAD/CAM resin blocks are considered as alternative materials to glass-ceramics. However, one clinical study up to 3 years of function observed that resin single-tooth restorations had inferior success rates compared to all ceramic ones ${ }^{11)}$. This was due to the inferior esthetics and wear resistance of resin crowns. Therefore the authors stated that all-ceramic crowns remain the preferred treatment material for
CAD/CAM-generated metal-free single restorations. Discoloration still seem to be the limitary factor for resin based materials.

FDP materials must maintain long-term color stability in order to avoid replacement of restorations. Regardless of their chemical composition, dental resins tend to absorb liquids ${ }^{12}$. Therefore, discoloration may occur over time when subjected to various media, such as coffee, tea, red wine, chlorhexidine or bleaching agents ${ }^{13-16)}$. Color differences $(\Delta E)$ more than 3.3 units reflect clinically significant visual discoloration ${ }^{17,18)}$. The degree of discoloration of resins can be influenced by a number of factors such as incomplete polymerization, water sorption, chemical reactivity, diet, oral hygiene or surface roughness of the restoration ${ }^{19-21)}$. Discoloration can be due to extrinsic or intrinsic cause. Extrinsic causes include accumulation of plaque and surface stains, alterations of surface or subsurface color, implying a superficial degradation or a slight penetration and reaction of staining agents within the superficial layer of resin composites ${ }^{22}$. Subsequent polishing of the surface in particular can eliminate extrinsic causes, but if deeper layers are involved, the discoloration is mostly irreversible. The intrinsic discolorations mainly depend on the system of initiator systems used in the resins as well as on the applied form and duration of polymerization ${ }^{23,24)}$. They are caused by chemical changes in the material matrices and therefore concern all layers of the material.

Various techniques have been employed to elicit discoloration of temporary resins ${ }^{15,25-33)}$. Accelerated 
aging has been used to study the effect of a discoloration on both PMMA-based and composite resins demonstrating that clinically perceptible discoloration are likely to occur in some of the tested resins ${ }^{26,27,30,32)}$. Other studies have used immersion solutions such as artificial saliva, coffee, tea, grape juice, and chlorhexidine and at different time intervals compared their effects on discoloration of temporaries and direct restorative resins ${ }^{15,26,30,31)}$. To the author's best knowledge at present there is no information on the clinical and laboratory discoloration of the newly introduced $\mathrm{CAD} / \mathrm{CAM}$ resin reconstructions.

Therefore, the purpose of this study was to evaluate the effect of coffee, black tea and red wine storage on discoloration of five CAD/CAM and four manually polymerized resins, and to compare the results obtained with the control group (glass-ceramic). The first hypothesis was to test whether the CAD/CAM resins show similar discoloration compared to glass-ceramic. The second hypothesis was to test whether the CAD/ CAM resins show lower discoloration compared to manually polymerized ones.

\section{MATERIALS AND METHODS}

This study included five CAD/CAM resins: Blanc High-class (HC), ZENO PMMA (ZP), artBloc Temp (AT), artegral ImCrown (AI) and CAD-Temp (CT), four manually polymerized resins: Unifast III (UF), Gradia
(GD), CronMix K (CM) and Integral esthetic press (IE) and one glass-ceramic empressCAD (CG) as control group (Table 1).

Specimens were prepared $(N=300, n=30$ per material group) with a diameter of $15 \mathrm{~mm}$ and a thickness of 1 $\mathrm{mm}$, following the ISO 4049 specification. A plastic split ring that rested on a glass plate was used to fabricate the manually polymerized specimens. The resins were filled into the split ring between two glass plate and polymerized. UF and IE were polymerized in the polymerization pressure pot $\left(30 \mathrm{~min}, 45^{\circ} \mathrm{C}, 2.5 \mathrm{~min}\right.$, Ivomat, Ivoclar Vivadent, Schaan, Liechtenstein) according to the manufacturer's instructions. For GC, the GC LaboLight LV-III (GC Europe, Leuven, Belgium) was used for a polymerization time of 5 min according to the manufacturer. The CAD/CAM blocks were cut in disks with a thickness of $1 \mathrm{~mm}$ using a low-speed diamond saw (Well Diamantdrahtsägen, Mannheim, Germany) under water-cooling. Thereafter the edges were rounded using a dental bur (Komet H251 EF, Gebr. Brasseler, Lemgo, Germany). All specimens were embedded in acrylic resin (ScandiQuick, SCAN-DIA, Hagen, Germany) in cylindrical molding cups with a diameter of $25 \mathrm{~mm}$.

The specimen surfaces were polished for $4.5 \mathrm{~min}$ (P400, P1200, P2400) in a polishing device (LaboPol-21, Struers, Ballerup, Denmark) under standardized conditions and examined under an optical microscope

Table 1 The test groups, abbreviations, brands, batch numbers, manufacturers and composition of the tested materials

\begin{tabular}{|c|c|c|c|c|}
\hline Test group & Abbreviation & Batch No. & Manufacturer & Composition \\
\hline Blanc High-class & $\mathrm{HC}$ & 2007000908 & $\begin{array}{l}\text { Creamed, Marburg, } \\
\text { Germany }\end{array}$ & Bis-GMA, UDMA, nanofilled \\
\hline ZENO PMMA & $\mathrm{ZP}$ & 0483 & $\begin{array}{l}\text { Wieland Dental + Technik, } \\
\text { Pforzheim, Germany }\end{array}$ & PMMA, unfilled \\
\hline artBloc Temp & $\mathrm{AT}$ & 13708 & $\begin{array}{l}\text { Merz Dental, Lütjenburg, } \\
\text { Germany }\end{array}$ & PMMA, unfilled \\
\hline artegral ImCrown & $\mathrm{AI}$ & 2275 & $\begin{array}{l}\text { Merz Dental, Lütjenburg, } \\
\text { Germany }\end{array}$ & PMMA, unfilled \\
\hline CAD-Temp & $\mathrm{CT}$ & 19180 & $\begin{array}{l}\text { Vita Zahnfabrik, Bad } \\
\text { Säckingen, Germany }\end{array}$ & PMMA, micro-filled \\
\hline Unifast III & $\mathrm{UF}$ & $\begin{array}{l}0709103 \\
0909041\end{array}$ & $\begin{array}{l}\text { GC Europe. Leuven, } \\
\text { Belgium }\end{array}$ & PMMA, unfilled \\
\hline Gradia & GD & 0809032 & $\begin{array}{l}\text { GC Europe. Leuven, } \\
\text { Belgium }\end{array}$ & UDMA, EDMA, fine-hybrid filled \\
\hline CronMix K & $\mathrm{CM}$ & 592308 & $\begin{array}{l}\text { Merz Dental, Lütjenburg, } \\
\text { Germany }\end{array}$ & UDMA, HEMA, filled \\
\hline $\begin{array}{l}\text { Integral esthetic } \\
\text { press }\end{array}$ & IE & $\begin{array}{l}1 / 4106 \\
2 \mathrm{X} 2216\end{array}$ & $\begin{array}{l}\text { Merz Dental, Lütjenburg, } \\
\text { Germany }\end{array}$ & PMMA, unfilled \\
\hline Empress CAD & $\mathrm{GC}$ & JM0355 & $\begin{array}{l}\text { Ivoclar Vivadent, Schaan, } \\
\text { Liechtenstein }\end{array}$ & $\begin{array}{l}\mathrm{SiO}_{2}, \mathrm{BaO}, \mathrm{Al}_{2} \mathrm{O}_{3}, \mathrm{CaO}, \mathrm{CeO}_{2}, \mathrm{Na}_{2} \mathrm{O}, \\
\mathrm{K}_{2} \mathrm{O}, \mathrm{B}_{2} \mathrm{O}_{3}, \mathrm{TiO}_{2}\end{array}$ \\
\hline
\end{tabular}

Bis-GMA: bisphenol-A-glycidyl methacrylate; UDMA: urethan dimethacrylate, PMMA: polymethyl methacrylate, EDMA: ethylen glucol dimethylmethacrylate, HEMA: 2-hydroxyethyl methacrylate. 
(25×, Wild M3B, Heerbrugg, Switzerland). Each material group was randomly divided in three subgroups: (1) storage in coffee (Mastro Lorenzo Classico, Kraft Foods, Glattpark, Switzerland) at $37^{\circ} \mathrm{C}(n=10)$, (2) storage in black tea (Lipton Yellow Label, Unilever, Thayngen, Switzerland) at $37^{\circ} \mathrm{C}(n=10)$, and (3) storage in red wine (Rioja, Spain) at $37^{\circ} \mathrm{C}(n=10)$.

The discoloration of each specimen was measured before aging and after 1, 7, 28, 90 and 180 days storage. The initial measurement of each group was considered as baseline measurements. The measurements were performed with a calibrated (white standard SRS-99010-7698-a) spectrophotometer (CM-508d, Minolta, Tokyo, Japan). The resulting parameters $(L, a, b)$ were examined by illuminant D65 using the software (SpectraMagic, Minolta). Then the $\Delta E$-values were calculated with the following formula: $\Delta E=\sqrt{\Delta a^{2}+\Delta b^{2}-\Delta L^{2}}$ $(\Delta E$ : general difference in color changes, $\Delta a$ : difference in color change in the red-green-axis, $\Delta b$ : difference in color change in the yellow-blue-axids, $\Delta L$ : difference in brightness). After 180 days of storage in coffee, black tea and red wine, all specimens were polished for $60 \mathrm{~s}$ with a prophylaxis paste (Cleanic, KerrHawe SA, Bioggio, Switzerland) and the color was measured again.

\section{Statistical analysis}

Descriptive statistics (mean, SD) were computed. Linear mixed models with baseline of glass-ceramic were applied to investigate the influence of the material, storage time and the interaction between them for all three storage mediums separately. The paired $t$-test was applied in order to evaluate the impact of polishing compared to specimens stored for 180 days. The Statistical Package for the Social Science Version 19 (SPSS INC, Chicago, IL, USA) was used. All results with $p$-values less than $5 \% \quad(p<0.05)$ were considered as statistically significant.

\section{RESULTS}

Descriptive statistics (mean, SD) of the measured discoloration $(\Delta L, \Delta a, \Delta b, \Delta E)$ at all aging levels stored in coffee, black tea or red wine of each tested resin and the control group is presented in Table 2 .

One CAD/CAM composite $\mathrm{HC}$ and two manually polymerized resin composites GD and CM showed initially higher $\Delta E$ in coffee storage compared to the control group $(p \leq 0.002)$. Significantly higher increase in $\Delta E$ in coffee storage was observed for the manually polymerized resins GD and CM than for the control group $(p \leq 0.015)$. Significantly less increase in $\Delta E$ was obtained for the control group compared to the PMMA-based CAD/CAM resins AT and CT $(p \leq 0.028)$ (Fig. 1).

Among the black tea storage groups, the CAD/CAM resins $\mathrm{HC}$ and $\mathrm{AT}$ and the manually polymerized resin composite GD showed initially significantly higher $\Delta E$ compared to the control group $(p \leq 0.027)$. CAD/CAM

Table 2 Descriptive statistics for discoloration $(\Delta E)$ at each time point for all tested groups and paired $t$-test $p$-values for the effect of polishing

\begin{tabular}{|c|c|c|c|c|}
\hline \multirow{2}{*}{ Test material } & \multirow{2}{*}{ Aging level (days) } & \multicolumn{3}{|c|}{ mean \pm SD } \\
\hline & & coffee & Black tea & Red wine \\
\hline \multirow{7}{*}{$\mathrm{HC}$} & 1 & $3.52 \pm 1.9$ & $3.25 \pm 1.6$ & $3.87 \pm 2.4$ \\
\hline & 7 & $5.99 \pm 2.3$ & $3.14 \pm 2$ & $7.6 \pm 3.7$ \\
\hline & 28 & $6.91 \pm 3.5$ & $4.47 \pm 2.3$ & $9.83 \pm 3.9$ \\
\hline & 90 & $7.08 \pm 3.6$ & $8.97 \pm 3$ & $19.27 \pm 6.7$ \\
\hline & 180 & $7.34 \pm 3.7$ & $14.04 \pm 3.1$ & $21.6 \pm 6$ \\
\hline & $t$-test & $<0.001$ & 0.096 & $<0.001$ \\
\hline & After polishing & $4.42 \pm 3.2$ & $12.04 \pm 4$ & $5.2 \pm 3.2$ \\
\hline \multirow{7}{*}{$\mathrm{ZP}$} & 1 & $0.9 \pm 1$ & $0.74 \pm 0.5$ & $1.28 \pm 0.3$ \\
\hline & 7 & $1.11 \pm 1$ & $1.09 \pm 0.4$ & $2.1 \pm 0.3$ \\
\hline & 28 & $1.55 \pm 0.7$ & $1.57 \pm 0.5$ & $1.5 \pm 0.4$ \\
\hline & 90 & $1.09 \pm 0.8$ & $1.52 \pm 0.5$ & $2.24 \pm 0.7$ \\
\hline & 180 & $1.17 \pm 0.8$ & $1.81 \pm 0.6$ & $1 \pm 0.1$ \\
\hline & $t$-test & 0.091 & 0.026 & 0.536 \\
\hline & After polishing & $1.66 \pm 0.9$ & $1.3 \pm 0.8$ & $0.94 \pm 0.3$ \\
\hline \multirow{7}{*}{ AT } & 1 & $3.96 \pm 2.1$ & $2.5 \pm 2.1$ & $1.29 \pm 1.5$ \\
\hline & 7 & $2.19 \pm 0.5$ & $1.97 \pm 1.8$ & $2.17 \pm 1.5$ \\
\hline & 28 & $2.9 \pm 2.8$ & $2.73 \pm 2.5$ & $2.36 \pm 2.3$ \\
\hline & 90 & $1.91 \pm 0.7$ & $1.79 \pm 1.5$ & $2.89 \pm 1.9$ \\
\hline & 180 & $1.77 \pm 0.9$ & $2.26 \pm 2.1$ & $1.2 \pm 0.5$ \\
\hline & $t$-test & 0.004 & 0.001 & 0.053 \\
\hline & After polishing & $2.77 \pm 1.6$ & $3.23 \pm 2.1$ & $0.69 \pm 0.4$ \\
\hline
\end{tabular}


Table 2 (continued)

\begin{tabular}{|c|c|c|c|c|}
\hline \multirow{2}{*}{ Test material } & \multirow{2}{*}{ Aging level (days) } & \multicolumn{3}{|c|}{ mean \pm SD } \\
\hline & & coffee & Black tea & Red wine \\
\hline \multirow{7}{*}{$\mathrm{AI}$} & 1 & $1.13 \pm 0.4$ & $0.62 \pm 0.3$ & $1.12 \pm 0.9$ \\
\hline & 7 & $1.76 \pm 1.1$ & $1.22 \pm 0.4$ & $2.42 \pm 1.7$ \\
\hline & 28 & $1.46 \pm 0.8$ & $1.44 \pm 0.5$ & $7.5 \pm 4$ \\
\hline & 90 & $1.1 \pm 0.5$ & $1.53 \pm 0.3$ & $1.66 \pm 0.8$ \\
\hline & 180 & $1.5 \pm 0.4$ & $0.88 \pm 0.5$ & $3.23 \pm 2.8$ \\
\hline & $t$-test & 0.032 & $<0.001$ & 0.015 \\
\hline & After polishing & $1.13 \pm 0.4$ & $1.62 \pm 0.7$ & $1.12 \pm 0.9$ \\
\hline \multirow{7}{*}{$\mathrm{CT}$} & 1 & $1.57 \pm 1.3$ & $1.96 \pm 4.1$ & $2.19 \pm 4$ \\
\hline & 7 & $2.47 \pm 1.6$ & $2.46 \pm 2.5$ & $2.88 \pm 3.4$ \\
\hline & 28 & $1.48 \pm 0.9$ & $1.31 \pm 0.8$ & $2.14 \pm 3.7$ \\
\hline & 90 & $1.48 \pm 1.1$ & $1.2 \pm 0.6$ & $2.45 \pm 3.6$ \\
\hline & 180 & $1.71 \pm 1.7$ & $1.04 \pm 0.9$ & $2.17 \pm 4.1$ \\
\hline & $t$-test & 0.068 & 0.004 & $<0.001$ \\
\hline & After polishing & $2.03 \pm 1.4$ & $1.5 \pm 1.1$ & $2.7 \pm 4.2$ \\
\hline \multirow{7}{*}{$\mathrm{UF}$} & 1 & $1.61 \pm 1.1$ & $0.94 \pm 0.1$ & $1.62 \pm 0.4$ \\
\hline & 7 & $2.04 \pm 1$ & $0.7 \pm 0.4$ & $1.33 \pm 0.6$ \\
\hline & 28 & $2.59 \pm 1.1$ & $1.36 \pm 0.2$ & $9.92 \pm 6.4$ \\
\hline & 90 & $2.82 \pm 1.1$ & $0.68 \pm 0.1$ & $9.25 \pm 11.4$ \\
\hline & 180 & $3.36 \pm 1.5$ & $2.48 \pm 0.4$ & $11.76 \pm 13$ \\
\hline & $t$-test & 0.003 & 0.001 & 0.124 \\
\hline & After polishing & $2.02 \pm 0.7$ & $2.14 \pm 0.4$ & $6.37 \pm 4.1$ \\
\hline \multirow{7}{*}{ GD } & 1 & $4.6 \pm 4.9$ & $1.19 \pm 0.7$ & $5.29 \pm 3.9$ \\
\hline & 7 & $7.78 \pm 3.9$ & $1.88 \pm 0.9$ & $11.01 \pm 0.9$ \\
\hline & 28 & $8.92 \pm 3.7$ & $4.64 \pm 2$ & $17.14 \pm 7$ \\
\hline & 90 & $9.72 \pm 5.3$ & $2.52 \pm 1.6$ & $18.26 \pm 6.1$ \\
\hline & 180 & $12.68 \pm 5.3$ & $3.27 \pm 2$ & $22.29 \pm 6.1$ \\
\hline & $t$-test & $<0.001$ & 0.007 & $<0.001$ \\
\hline & After polishing & $7.13 \pm 3.5$ & $0.96 \pm 0.4$ & $11.53 \pm 4$ \\
\hline \multirow{7}{*}{$\mathrm{CM}$} & 1 & $3.21 \pm 2.2$ & $1.25 \pm 0.7$ & $4.07 \pm 2$ \\
\hline & 7 & $4.92 \pm 3.1$ & $1.92 \pm 0.9$ & $9.53 \pm 3.6$ \\
\hline & 28 & $5.36 \pm 3.3$ & $3.15 \pm 2.3$ & $16.38 \pm 3.6$ \\
\hline & 90 & $5.76 \pm 4.5$ & $5.3 \pm 5.6$ & $19.32 \pm 5$ \\
\hline & 180 & $7.33 \pm 3.7$ & $5.1 \pm 5.3$ & $22.87 \pm 5.7$ \\
\hline & $t$-test & 0.018 & 0.804 & $<0.001$ \\
\hline & After polishing & $5.82 \pm 4$ & $4.98 \pm 6$ & $5.82 \pm 1.84$ \\
\hline \multirow{7}{*}{ IE } & 1 & $1.1 \pm 0.2$ & $0.98 \pm 0.1$ & $1.17 \pm 0.1$ \\
\hline & 7 & $1.37 \pm 0.1$ & $1.45 \pm 0.1$ & $1.84 \pm 0.2$ \\
\hline & 28 & $0.76 \pm 0.1$ & $0.47 \pm 0.1$ & $6 \pm 3.2$ \\
\hline & 90 & $2.73 \pm 0.3$ & $2.6 \pm 0.2$ & $5.46 \pm 2.2$ \\
\hline & 180 & $0.71 \pm 0.2$ & $0.86 \pm 0.1$ & $2.14 \pm 0.9$ \\
\hline & $t$-test & 0.026 & $<0.001$ & 0.012 \\
\hline & After polishing & $1.24 \pm 0.6$ & $2.08 \pm 0.4$ & $1.1 \pm 0.2$ \\
\hline \multirow{7}{*}{ CG } & 1 & $0.67 \pm 0.6$ & $0.83 \pm 0.5$ & $1.02 \pm 0.6$ \\
\hline & 7 & $1.6 \pm 1.1$ & $0.97 \pm 0.7$ & $1.58 \pm 1$ \\
\hline & 28 & $1.87 \pm 1.1$ & $0.77 \pm 0.1$ & $3.26 \pm 2.5$ \\
\hline & 90 & $2.16 \pm 1.6$ & $2.74 \pm 0.9$ & $2.02 \pm 1$ \\
\hline & 180 & $2.52 \pm 2.1$ & $2.83 \pm 1$ & $1.69 \pm 0.9$ \\
\hline & $t$-test & $<0.001$ & $<0.001$ & 0.571 \\
\hline & After polishing & $2.26 \pm 2.1$ & $2.77 \pm 0.9$ & $1.84 \pm 1.3$ \\
\hline
\end{tabular}




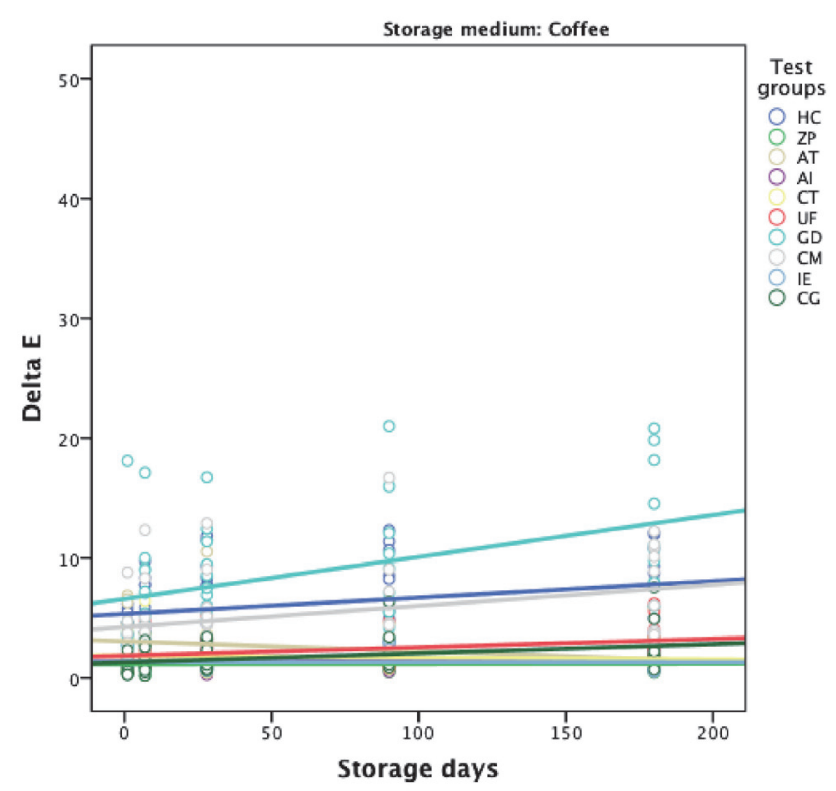

Fig. 1 Discoloration ( $\Delta E$ ) after coffee storage for each tested group at each aging level.

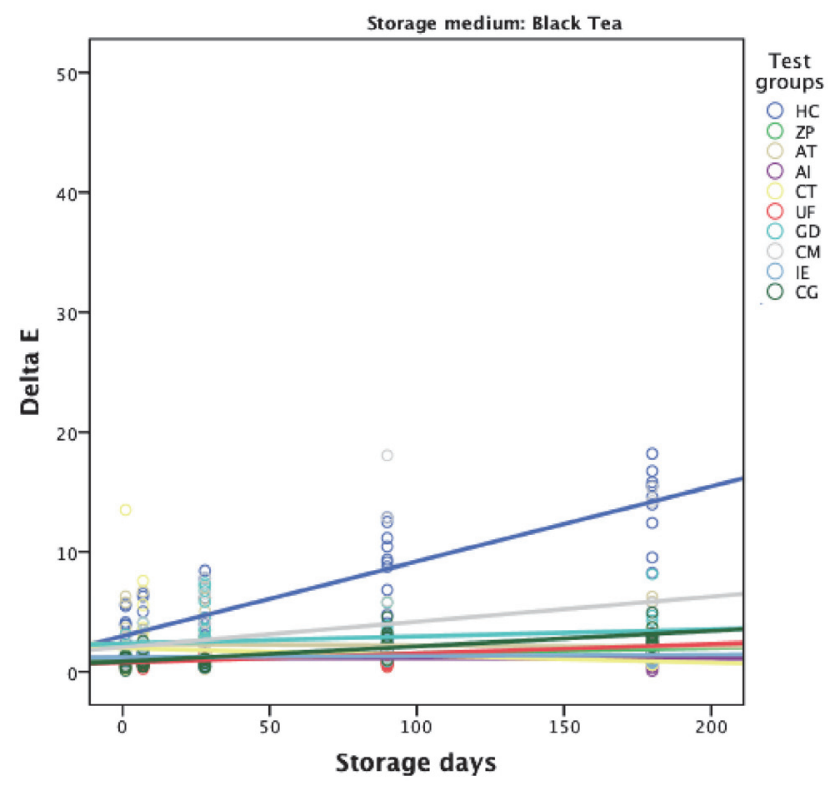

Fig. 2 Discoloration $(\Delta E)$ after black tea storage for each tested group at each aging level.

resin $\mathrm{HC}$ and manually polymerized resin CM presented higher increase in $\Delta E$ than the control group $(p \leq 0.047)$. For the CAD/CAM resins AT, AI and CT, and for the manually polymerized PMMA-based resin IE less increase in $\Delta E$ were observed ( $p \leq 0.005)$ (Table 2, Fig. 2).

Regarding to the red wine storage, CAD/CAM resin composite HC and two manually polymerized resin composites GD and CM showed significantly higher $\Delta E$ than the control group at baseline $(p \leq 0.002)$. These

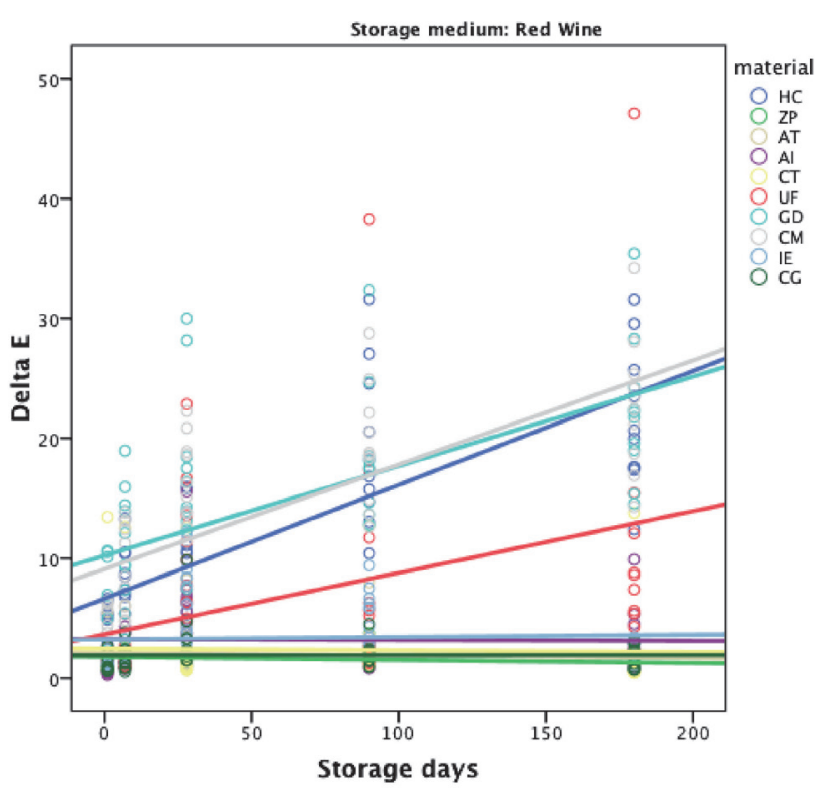

Fig. 3 Discoloration $(\Delta E)$ after red wine storage for each tested group at each aging level.

groups together with the manually polymerized PMMA-based resin UF showed higher increase of $\Delta E$ than the control group ( $p<0.001)$ (Table 2, Fig. 3).

After polishing using a prophylaxis paste to remove the discoloration $\Delta E$ of all tested groups presented decreased $\Delta E$ less than 3.3 in all media. Only, the composite-based materials GD, CM and $\mathrm{HC}$ showed higher discoloration about $3.3 \Delta E$ in all media after polishing.

\section{DISCUSSION}

Resins for temporary FDPs and the tested glass-ceramic underwent color change when exposed to various storage media. According to the results of this study, overall in all storage media, the discoloration of the manually polymerized composites GD and CM was significantly higher compared to manually polymerized PMMA-based resins, industrially polymerized $\mathrm{CAD} / \mathrm{CAM}$ blocks and glass-ceramic. Only one composite-based CAD/CAM resin, HC showed significantly higher discoloration than the glass-ceramic. $\Delta E$ of the remaining $\mathrm{CAD} / \mathrm{CAM}$ resins was not significantly different compared to glass-ceramic. Therefore, both hypotheses of this study that CAD/CAM resins show similar discolorations compared to glassceramic and lower discoloration compared to manually polymerized resins are rejected. This study showed that the composites showed higher discoloration compared to PMMA-based resins. Other studies reported that the resin matrix used in the composite-based materials have an important impact on discoloration ${ }^{20,24,34,35)}$. UDMA seems to be more color-resistant than Bis-GMA because of its low water absorption and solubility characteristics ${ }^{36)}$. Discoloration of Bis-GMA monomer is attributed to the 
-OH groups in this monomer that yields to more water sorption. Water uptake in Bis-GMA-based resins was shown to increase from 3 to $6 \%$ as the proportion of TEGDMA increased from 0 to $1 \%{ }^{35)}$. In this study, the manually polymerized composites were based on UDMA, and $\mathrm{HC} \mathrm{CAD} / \mathrm{CAM}$ resin was based on Bis-GMA and UDMA. This can be the reason why $\mathrm{HC}$ specimens stored in black tea showed after polishing higher discoloration than both UDMA-based resins.

Considering baseline measurements, the polymerization type of the resins had no significant impact on the discoloration. The storage duration in all media of all tested groups had a significant impact on the color stability. The composites showed higher increase in discoloration in respect to the storage duration more than the PMMA-based ones. Several studies indicated that some PMMA-based resins tend to discolor less than other temporaries, including dimethyl methacrylate (composites) ${ }^{15,25,31,32)}$. Most dimethacrylates are more polar than the mono methacrylate PMMA and therefore have a greater affinity towards water and other polar liquids ${ }^{33)}$. However, other studies have also demonstrated that there are resin composite materials presenting similar color stability ${ }^{27,32)}$.

The composite-based CAD/CAM block, HC probably polymerized insufficiently. Unfortunately, polymerization process details were not available from the manufacturer for this material. This CAD/CAM block showed redress color differences at several layers that were already visually evident. The discoloration with this material can be explained by the fact that polymerization parameters (temperature, time, press) of those blocks were not satisfactory that yielded to absorption of the storage media. Although HC consists of Bis-GMA and UDMA the percentages of these methacrylate monomers could have affected the results. In return, all other CAD/ CAM blocks showed visually homogeneous structure. This study tested the discoloration for two different composite-based CAD/CAM blocks. For the other composite-based CAD/CAM block, CT showed comparable color stability with the glass-ceramic and with the other PMMA-based CAD/CAM resins.

In the present study, the discoloration of tested resins was dependent on storage duration and storage media. Similar observations were made in another in-vitro study for manually polymerized resins after 180 days, and the discoloration increased in ascending order with the black tea, coffee and red wine ${ }^{37)}$. In other previous studies red wine was reported to produce the most severe discoloration in temporary resins, followed by coffee and tea ${ }^{38,39)}$. In this study $\Delta E$ values were equal to or greater than 3.3 that considered to be clinically perceptible, based on previous reports ${ }^{16,17)}$. After polishing, the $\Delta E$ values for black tea, coffee, and red wine decreased to below $3.3 \Delta E$ and were therefore clinically acceptable, except for the manually polymerized composites GD, CM and the CAD/CAM composite HC.

The surface smoothness and roughness have direct impact to the susceptibility to extrinsic staining. In this study all specimens were polished in a standardized device for $4.5 \mathrm{~min}$ and for this reason, the measured color stability between the tested groups could be considered comparable.

Based on the findings, the CAD/CAM resins (except HC) showed comparable results with glass-ceramic. However, discoloration is only one variable that must be considered when choosing a material for long-term reconstructions. Discoloration is perhaps of great importance to patients and clinicians when working in the esthetic zone. Further studies should test other factors such as mechanical stability, wear and bond strength to cements. From the clinical point of view, in contrast to common clinical opinions, PMMA-based $\mathrm{CAD} / \mathrm{CAM}$ resins tested showed similar discoloration values compared to glass-ceramic ones. This CAD/CAM resins could be alternative materials to glass-ceramic for FDP constructions at least for long-term provisionals. However, clinical longevity of these materials is not known to date. When $\mathrm{CAD} / \mathrm{CAM}$ resins could replace glass-ceramics from optical and mechanical perspectives, they could be clinically utilized. Further clinical studies should be also considering antagonist enamel or restoration material wear against glass-ceramic versus CAD/CAM resins.

\section{CONCLUSIONS}

Within the limitations of this in-vitro study, the following conclusions can be drawn:

1. Four of the five tested CAD/CAM resins exhibited similar color stability compared to control group, glass-ceramic.

2. PMMA-based industrially and manually polymerized resins showed similar color stability.

3. Composite-based resins presented higher discoloration than the PMMA-based ones, except CT.

4. After polishing, the discoloration of all materials stored in black tea, coffee, and red wine decreased for PMMA-based materials.

\section{ACKNOWLEDGMENTS}

The authors would like to thank Merz Dental, Wieland+Dental, GC Europe, Ivoclar Vivadent and Vita Zahnfabrik for their support with the materials.

\section{REFERENSES}

1) Alt V, Hannig M, Wostmann B, Balkenhol M. Fracture strength of temporary fixed partial dentures: CAD/CAM versus directly fabricated restorations. Dent Mater 2011; 27: 339-347.

2) Goncu Basaran E, Ayna E, Vallittu PK, Lassila LV. Loadbearing capacity of handmade and computer-aided design computer-aided manufacturing-fabricated three-unit fixed dental prostheses of particulate filler composite. Acta Odontol Scand 2011; 69: 144-150.

3) Stawarczyk B, Ender A, Trottmann A, Özcan M, Fischer J, Hämmerle CH. Load-bearing capacity of CAD/CAM milled polymeric three-unit fixed dental prostheses: Effect of aging 
regimens. Clin Oral Investig 2012 (in press).

4) Banerjee R, Banerjee S, Prabhudesai PS, Bhide SV. Influence of the processing technique on the flexural fatigue strength of denture base resins: an in vitro investigation. Indian J Dent Res 2010; 21: 391-395.

5) Rocca GT, Bonnafous F, Rizcalla N, Krejci I. A technique to improve the esthetic aspects of CAD/CAM composite resin restorations. J Prosthet Dent 2010; 104: 273-275.

6) Anusavice KJ, Phillips R. Phillips' science of dental materials. 11th ed. St. Louis: Elsevier; 2003.

7) Lin CL, Chang YH, Liu PR. Multi-factorial analysis of a cuspreplacing adhesive premolar restoration: A finite element study. J Dent 2008; 36: 194-203.

8) Attia A, Abdelaziz KM, Freitag S, Kern M. Fracture load of composite resin and feldspathic all-ceramic CAD/CAM crowns. J Prosthet Dent 2006; 95: 117-123.

9) Giordano R. Materials for chairside CAD/CAM-prodeced restorations. J Am Dent Assoc 2006; 137: 14S-21S.

10) Magne P, Knezevic A. Simulated fatigue resistance of composite resin versus porcelain CAD/CAM overlay restorations on endodontically treated molars. Quintessence Int 2009; 40: 125-133.

11) Vanoorbeek S, Vandamme K, Lijnen I, Naert I. Computeraided designed/computer-assisted manufactured composite resin versus ceramic single-tooth restorations: a 3-year clinical study. Int J Prosthodont 2010; 23: 223-230.

12) Della Bona A, Anusavice KJ, Mecholsky JJ, Jr. Failure analysis of resin composite bonded to ceramic. Dent Mater 2003; 19: 693-699.

13) Um CM, Ruyter IE. Staining of resin-based veneering materials with coffee and tea. Quintessence Int 1991; 22: 377-386.

14) Khokhar ZA, Razzoog ME, Yaman P. Color stability of restorative resins. Quintessence Int 1991; 22: 733-737.

15) Scotti R, Mascellani SC, Forniti F. The in vitro color stability of acrylic resins for provisional restorations. Int J Prosthodont 1997; 10: 164-168.

16) Robinson FG, Haywood VB, Myers M. Effect of 10 percent carbamide peroxide on color of provisional restoration materials. J Am Dent Assoc 1997; 128: 727-731.

17) Imazato S, Tarumi H, Kobayashi K, Hiraguri H, Oda K, Tsuchitani Y. Relationship between the degree of conversion and internal discoloration of light-activated composite. Dent Mater J 1995; 14: 23-30.

18) Rueggeberg FA, Margeson DH. The effect of oxygen inhibition on an unfilled/filled composite system. J Dent Res 1990; 69: 1652-1658.

19) Patel SB, Gordan VV, Barrett AA, Shen C. The effect of surface finishing and storage solutions on the color stability of resin-based composites. J Am Dent Assoc 2004; 135: 587-594.

20) Turkun LS, Turkun M. Effect of bleaching and repolishing procedures on coffee and tea stain removal from three anterior composite veneering materials. J Esthet Restor Dent 2004; 16: 290-301.

21) Satou N, Khan AM, Matsumae I, Satou J, Shintani H. In vitro color change of composite-based resins. Dent Mater 1989; 5:
384-387.

22) Nasim I, Neelakantan P, Sujeer R, Subbarao CV. Color stability of microfilled, microhybrid and nanocomposite resins —an in vitro study. J Dent 2010; 38 Suppl 2: e137-e142.

23) Hosoya Y. Five-year color changes of light-cured resin composites: influence of light-curing times. Dent Mater 1999; 15: 268-274.

24) Janda R, Roulet JF, Kaminsky M, Steffin G, Latta M. Color stability of resin matrix restorative materials as a function of the method of light activation. Eur J Oral Sci 2004; 112: 280-285.

25) Crispin BJ, Caputo AA. Color stability of temporary restorative materials. J Prosthet Dent 1979; 42: 27-33.

26) Yaman P, Razzoog M, Brandau HE. In vitro color stability of provisional restorations. Am J Dent 1989; 2: 48-50.

27) Doray PG, Wang X, Powers JM, Burgess JO. Accelerated aging affects color stability of provisional restorative materials. J Prosthodont 1997; 6: 183-188.

28) Robinson ME, Myers CD, Sadler IJ, Riley JL 3rd, Kvaal SA, Geisser ME. Bias effects in three common self-report pain assessment measures. Clinic J Pain 1997; 13: 74-81.

29) Hoshiai K, Tanaka Y, Hiranuma K. Comparison of a new autocuring temporary acrylic resin with some existing products. J Prosthet Dent 1998; 79: 273-277.

30) Lang R, Rosentritt M, Leibrock A, Behr M, Handel G. Colour stability of provisional crown and bridge restoration materials. Br Dent J 1998; 185: 468-471.

31) Yannikakis SA, Zissis AJ, Polyzois GL, Caroni C. Color stability of provisional resin restorative materials. J Prosthet Dent 1998; 80: 533-539.

32) Doray PG, Li D, Powers JM. Color stability of provisional restorative materials after accelerated aging. J Prosthodont 2001; 10: 212-216.

33) Haselton DR, Diaz-Arnold AM, Dawson DV. Color stability of provisional crown and fixed partial denture resins. J Prosthet Dent 2005; 93: 70-75.

34) Reis AF, Giannini M, Lovadino JR, Ambrosano GM. Effects of various finishing systems on the surface roughness and staining susceptibility of packable composite resins. Dent Mater 2003; 19: 12-18.

35) Bagheri R, Burrow MF, Tyas M. Influence of food-simulating solutions and surface finish on susceptibility to staining of aesthetic restorative materials. J Dent 2005; 33: 389-398.

36) Ertas E, Guler AU, Yucel AC, Koprulu H, Guler E. Color stability of resin composites after immersion in different drinks. Dent Mater J 2006; 25: 371-376.

37) Stawarczyk B, Egli R, Roos M, Özcan M, Hämmerle CHF. The impact of in vitro aging on the mechanical and optical properties of indirect veneering composite resins. J Prosthet Dent 2011; 106: 386-398.

38) Guler AU, Yilmaz F, Kulunk T, Guler E, Kurt S. Effects of different drinks on stainability of resin composite provisional restorative materials. J Prosthet Dent 2005; 94: 118-124.

39) Stober T, Gilde H, Lenz P. Color stability of highly filled composite resin materials for facings. Dent Mater 2001; 17: 87-94. 